This is a peer-reviewed, accepted author manuscript of the following article: Rodrigues, M. A., Rego, P., Geraldes, V., Connor, L. E., Oswald, I. D. H., Sztucki, M., \& Shalaev, E. (2021). Mannitol crystallization at sub-zero temperatures: time/temperatureresolved synchrotron x-ray diffraction study and the phase diagram. Journal of Physical Chemistry Letters, 12(5), 1453-1460. https://doi.org/10.1021/acs.jpclett.0c03680

\title{
Mannitol Crystallization at Sub-Zero Temperatures: \\ Time/Temperature-Resolved Synchrotron X-ray Diffraction Study and the Phase Diagram.
}

Miguel A Rodrigues, ${ }^{\mathrm{a}}$ Pedro Rego, ${ }^{\mathrm{a}}$ Vitor Geraldes, ${ }^{\mathrm{a}}$ Lauren E. Connor, ${ }^{\mathrm{b}, \mathrm{c}}$ Iain D. H. Oswald, ${ }^{\mathrm{b}, *}$ Michael Sztucki, ${ }^{\mathrm{d}}$ Evgenyi Shalaev. ${ }^{\mathrm{e}, *}$

${ }^{a}$ Centro de Química Estrutural, Instituto Superior Tecnico, University of Lisbon, Lisbon, Portugal.

${ }^{\mathrm{b}}$ Strathclyde Institute of Pharmacy and Biomedical Sciences, University of Strathclyde, 161 Cathedral Street, Glasgow, G4 0RE, U.K.

${ }^{\mathrm{c}}$ Collaborative International Research Programme: University of Strathclyde and Nanyang Technological University, Singapore, Technology Innovation Centre, 99 George Street, Glasgow, G1 1RD, U.K.

dEuropean Synchrotron Radiation Facility, 71 avenue des Martyrs, 38043 Grenoble Cedex 9, France.

e Pharmaceutical Sciences, Abbvie, 2525 Dupont Drive, Irvine, CA 92612, United States.

* Corresponding author. 


\begin{abstract}
.
Mannitol, a common pharmaceutical ingredient, exhibits complex polymorphism even in simple binary mannitol/water mixtures, with 4 crystalline forms observed. In this investigation, time/temperature resolved synchrotron X-ray diffraction measurements are performed during freezing and thawing of mannitol/water mixtures. Mannitol crystallization depends strongly on the cooling rate, and is initiated during cooling, if the cooling rate is lower than the critical cooling rate; otherwise, mannitol remains amorphous during freezing, and crystallizes during subsequent heating above $-30^{\circ} \mathrm{C}$. Temperature-composition phase diagram is constructed, reflecting eutectic and peritectic points, and lower-temperature equilibria involving mannitol hemihydrate, hexagonal ice, and $\beta$-mannitol. Comparing the experimental data with the phase diagram reveals that mannitol crystallization behavior does not follow the equilibrium but appears to obey the Ostwald crystallization rule. Novel insights on equilibrium and kinetics phase relationships in mannitol/water system could lead to improved formulations and manufacturing processes for pharmaceuticals and biopharmaceuticals.
\end{abstract}




\section{TOC GRAPHICS}

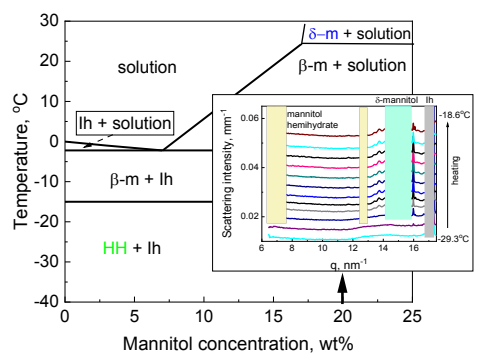

KEYWORDS: mannitol, crystallization, frozen solutions, synchrotron X-ray diffraction, phase diagram 
Frozen aqueous systems are ubiquitous both in nature and in various industrial applications, including, e.g., desalination by freeze crystallization, frozen food storage, and cryopreservation of biological drugs (biopharmaceuticals). Many modern biopharmaceuticals, including, e.g., gene therapy products and the newly developed Pfizer/BioNTech COVID-19 vaccine, are stored as frozen solutions. Also, freeze-drying (lyophilization), which is widely used for production of injectable drug products, includes freezing as the first manufacturing step. In the industrial applications, crystallization of solutes during freezing could have a major impact on both the process and properties of the final product, and study of solute crystallization is an essential part of scientific basis behind the technologies developed. ${ }^{1-3}$ Understanding solute crystallization during freezing is also essential in environmental science. ${ }^{4}$ The primary objective of this study is to examine solute crystallization behavior in one specific system, water-mannitol, which is directly relevant to pharmaceuticals and biopharmaceuticals; nevertheless, the results could be of a broader interest to scientists across various scientific communities.

A typical solution for freeze-drying contains an active ingredient and several inactive ingredients (excipients), such as a buffer, a lyoprotector, and a bulking agent. These excipients play a critical role in assuring stability and efficacy of pharmaceuticals. Freezing of a pharmaceutical solution usually starts with formation of hexagonal ice, while the phase behavior of the solutes depends on multiple factors, including their chemical nature, concentration, and temperature/time pathway. In many cases, crystallization of a solute is desirable, as it facilitates freeze-drying process and also assures more consistent long-term stability profile. ${ }^{1}$ However, there are also potential problems associated with the crystallization, including reduced product yield due to vial breakage during manufacture, instability during shelf life if the crystallization during freeze-drying is incomplete, and formation of a crystalline hydrate (vs an anhydrous crystalline polymorph); in the latter case, the product could fail residual water content test, resulting in lot-to-lot variability and in rejection of (already produced and expensive) drug product lots. Such crystallization-related issues have been observed for freeze-dried products containing a common pharmaceutical bulking agent, mannitol. ${ }^{5-9}$

Mannitol crystallization behavior is complicated even in simple binary mannitol-water mixtures, with at least 3 anhydrous polymorphs $(\alpha, \beta, \delta)$ and a hemihydrate $(\mathrm{HH})$ observed in both frozen 
and freeze-dried states. ${ }^{10-12}$ No clear conclusions have been reached on what form(s) can be expected to appear at different conditions, with one noticeable exception ${ }^{13}$, as discussed below in some details. Interpretation of the experimental data on phase relationships in mannitol-water mixtures at low temperatures is complicated by several factors, including a difficulty in reproducing results on mannitol polymorph formation even when experiments are performed in the same group under identical conditions ${ }^{13}$, a kinetic stability of metastable mannitol polymorphs, ${ }^{14}$ which means that a lack of conversion from one form to another does not necessarily indicate its thermodynamics stability, and also by the fact that the temperaturecomposition (T-x) water/mannitol phase diagram has not been reported in the literature. In addition to thermodynamics phase relationships, kinetic aspects of mannitol crystallization are also of a critical importance for industrial freeze-drying processes. For example, temperatures for the onset and completion of crystallization during freezing/warming are of a major practical significance, because they would provide a direct input into design of freezing and primary drying steps for freeze-drying manufacture. Several studies reported wide and variable temperature ranges for crystallization of different solid forms of mannitol during freezing 13, 15, 16 , with complicated patterns in amorphous-to-crystalline conversion and appearance of different crystalline forms observed.

In this study, time/temperature-resolved synchrotron XRD (sXRD) is used to investigate mannitol crystallization behavior in water/mannitol mixtures at sub-ambient temperatures at different mannitol concentrations $(5,10$, and $20 \mathrm{wt} \%)$ and cooling rates $\left(0.5\right.$ and $\left.5^{\circ} \mathrm{C} / \mathrm{min}\right)$. The cooling rates were selected based on initial DSC experiments, which indicated mannitol crystallization during cooling at $0.5^{\circ} \mathrm{C} / \mathrm{min}$, whereas the higher cooling rate resulted in amorphous mannitol which crystallized only during subsequent warming (Supporting Information). The experiments are performed at high brilliance beamline ID $02^{17}$ at the European Synchrotron Radiation Facility (ESRF), which allows time-resolved measurements due to its capability to generate high-quality patterns with exposure time of less than $0.1 \mathrm{sec}$. The temperature resolution of the Linkam stage, which is used to control the sample temperature during the experiments, is approx. $0.2^{\circ} \mathrm{C}$. The sXRD patterns are collected during both cooling and heating to monitor onset of mannitol and identify crystalline forms formed, as well as monitoring change in the crystallinity as a function of temperature. 


\section{Onset of Crystallization}

Representative X-ray diffraction patterns of the crystallization of $10 \mathrm{wt} \%$ mannitol solutions are shown in Figure 1. Depending on the cooling rate, mannitol crystallized either during cooling (Figure $1 \mathrm{~A}, 0.5^{\circ} \mathrm{C} / \mathrm{min}$ cooling) or heating (Figure $1 \mathrm{~B}, 5^{\circ} \mathrm{C} / \mathrm{min}$ ). For the $20 \mathrm{wt} \%$ mannitol solution the difference in crystallization behavior is also observed. During cooling at $0.5^{\circ} \mathrm{C} / \mathrm{min}$, mannitol crystallizes (Figure 2), but remains amorphous if cooled at a higher rate of $5^{\circ} \mathrm{C} / \mathrm{min}$ (Figure S4, Supporting Information). In the latter case, mannitol crystallized during subsequent heating at $-27^{\circ} \mathrm{C}$. Interestingly, for $5 \mathrm{wt} \%$ mannitol, the crystallization during cooling was incomplete (Figure 1C). In this case, mannitol crystallization started during cooling at $-18^{\circ} \mathrm{C}$; the crystallization stopped when the temperature reached $-28^{\circ} \mathrm{C}$, and resumed during subsequent heating. Similar crystallization patterns were also reported in ${ }^{13,15}$.

\section{Identification of solid forms of mannitol.}

To identify crystalline polymorphs of mannitol observed at different conditions, the experimental sXRD patterns were compared with reference patterns (see Materials and Methods for the sources of the reference patterns). Figure 2 shows examples for $20 \mathrm{wt} \%$ mannitol at cooling rate $0.5^{\circ} \mathrm{C} / \mathrm{min}$ at 2 temperatures. Patterns collected between $-9.2^{\circ} \mathrm{C}$ and $-14.4^{\circ} \mathrm{C}$ match reference pattern of $\beta$-mannitol (Figure 2A), whereas new peaks, which correspond to HH, appear after cooling below $-14.6^{\circ} \mathrm{C}$ (Figure 2B). Rietveld analysis of the phases is found in Figure S3A-C of supporting information. At the faster cooling rate of $5^{\circ} \mathrm{C} / \mathrm{min}$, when mannitol remained amorphous during cooling but crystallized on heating, the $\mathrm{HH}$ and $\delta$-form were observed (Figure S4B, Supporting Information). In addition, one extra weak peak was also detected which might indicate trace of $\alpha$-form (Figure S4C, Supporting information).

Cooling the $10 \mathrm{wt} \%$ solution at different rates also provided a similar change in solid form. The same 2 forms of crystalline mannitol ( $\mathrm{HH}$ and $\delta$ ) are detected during heating of the " $5{ }^{\circ} \mathrm{C} / \mathrm{min}$ " sample (Supporting Information, Figure S5A), whereas cooling of the same solution at 0.5 ${ }^{\circ} \mathrm{C} /$ min produced only one form $(\mathrm{HH})$ (Supporting Information, Figure $\mathrm{S} 5 \mathrm{~B}$ ). 

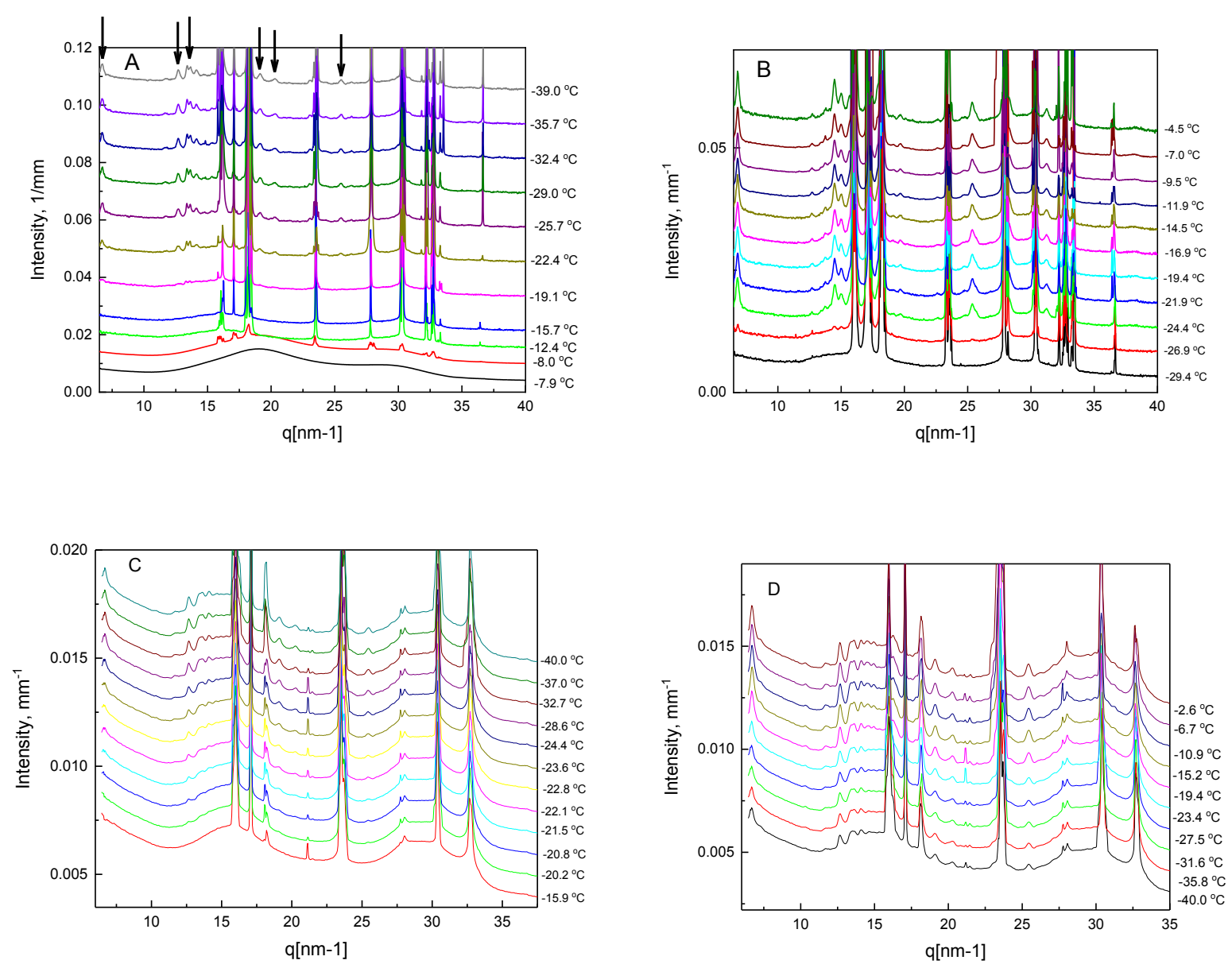

Figure 1. Representative sXRD patterns for $10 w t \%(A, B)$ and $5 w t \%$ mannitol solution (C, D). (A): $10 \mathrm{wt} \%$ during cooling at $0.5^{\circ} \mathrm{C} / \mathrm{min}$; arrows mark examples of peaks of crystalline mannitol; (B): $10 \mathrm{wt} \%$ during heating, after cooling at $5^{\circ} \mathrm{C} / \mathrm{min} ;(C): 5 \mathrm{wt} \%$ during cooling at $5^{\circ} \mathrm{C} / \mathrm{min}$; (D): $5 \mathrm{wt} \%$ during heating, after cooling at $5^{\circ} \mathrm{C} / \mathrm{min}$. The curves are shifted on the $y$ axis by $0.006 \mathrm{~mm}^{-1}$.

For the $5 \mathrm{wt} \%$ mannitol solution, a single crystalline form of mannitol $(\mathrm{HH})$ is observed (Supporting Information, Figure S6), although a trace quantity of $\beta$-form could also be present. Table S1 (Supporting Information) provides summary of mannitol forms detected at different conditions, as well as ice nucleation temperatures and the temperature ranges for mannitol crystallization. 
Integration of selected mannitol peaks was performed to quantify temperature trends in mannitol crystallinity. The peaks used for integration are marked with star in Table S2 (supporting information). Plots of peak areas vs temperature are shown in Figure 3 and Figure S7. The use of 2 or 3 diagnostic peaks for the same mannitol polymorph provided consistent results. For example, temperature trends for 2 peaks of the HH (6.8 and 12.7 1/nm, hkl $\left(\begin{array}{lll}0 & 1 & 0\end{array}\right)$ and $\left(\begin{array}{lll}0 & -1 & 1\end{array}\right)$, respectively) for $10 \%$ mannitol at cooling rate $0.5^{\circ} \mathrm{C} / \mathrm{min}$ are essentially identical (Figure $3 \mathrm{~A}$ ). In $10 \%$ and $20 \%$ solutions at cooling rate $0.5^{\circ} \mathrm{C} / \mathrm{min}$, crystallization of mannitol is complete during cooling, as no increase in the mannitol peaks was detected during subsequent warming of these samples (HH for 10\% mannitol, Figures S7A, and $\mathrm{HH}$ and $\beta$ for $20 \%$, Figures S7B and S7C, respectively, Supporting Information). Different trends are observed at the cooling rate of $5{ }^{\circ} \mathrm{C} / \mathrm{min}$. In the $5 \%$ sample (Figure $3 \mathrm{C}$ ), $\mathrm{HH}$ crystallization starts during cooling at $-18{ }^{\circ} \mathrm{C}$ and the corresponding peaks continue to grow down to approx. $-28^{\circ} \mathrm{C}$. Unusually, the crystallization resumes during subsequent heating at $-25^{\circ} \mathrm{C}$. A possible explanation of this behavior is that this temperature range $\left(-25\right.$ to $\left.-28^{\circ} \mathrm{C}\right)$ coincides with the temperature of an endothermal thermal transition observed by DSC, ${ }^{16,18,19}$ which is associated with a sharp decrease in the viscosity of the freeze-concentrated solution (see Supporting Information for a brief discussion of the lowtemperature thermal behavior).
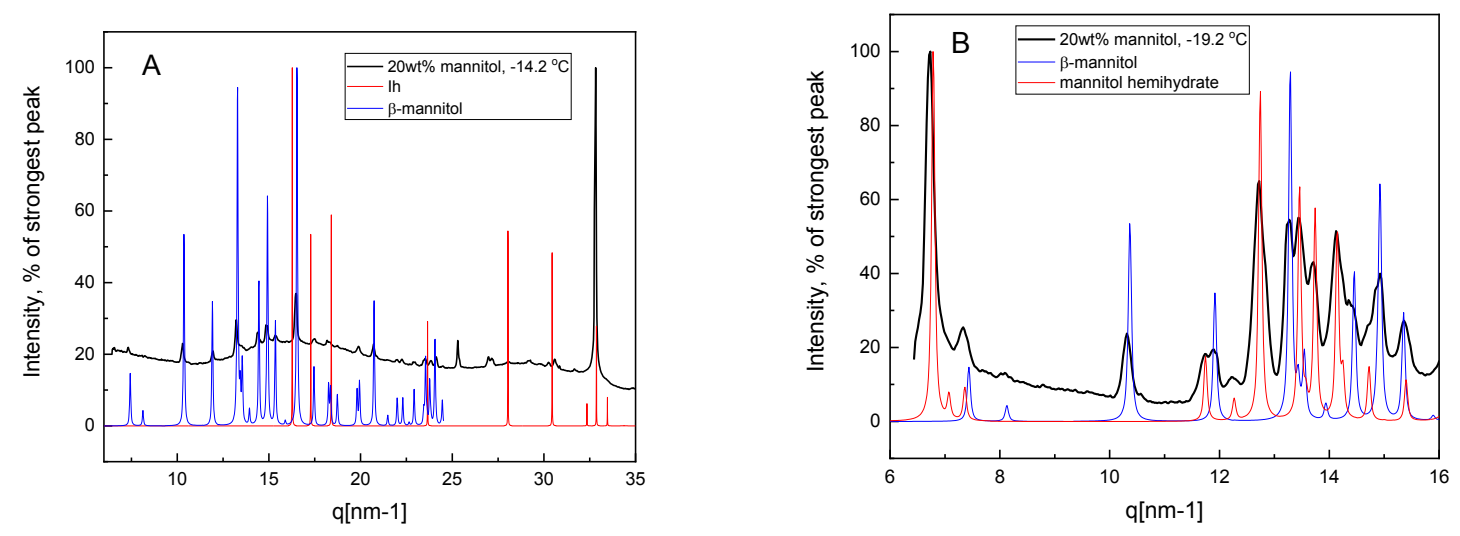

Figure 2. XRPD patterns for $20 \mathrm{wt} \%$ mannitol solution collected during cooling at the cooling rate of $0.5^{\circ} \mathrm{C} / \mathrm{min}$ at $-14.2^{\circ} \mathrm{C}(\mathrm{A})$, and $-19.2^{\circ} \mathrm{C}(B)$; see also Figure $S 2 B$ and Figures $S 3 A-S 3 C$, Supporting Information. Reference patterns for Ih, $\beta$-mannitol, and HH are also presented. 
The temperature dependence of the peak areas for delta-mannitol in 10 and $20 \%$ solutions $\left(5^{\circ} \mathrm{C} /\right.$ min, Figures $3 \mathrm{~B}$ and $3 \mathrm{D}$ ) shows 2 temperature regions, a lower-temperature (approx. -28 to $-25^{\circ} \mathrm{C}$ ) and higher-temperature region (above $-8^{\circ} \mathrm{C}$ for $10 \%$ and $-2.5^{\circ} \mathrm{C}$ for $20 \%$ sample). The second region (at higher-temperature) indicates an increase in the peak areas attributable to $\delta$ mannitol. Possible explanations for the increase may be due to a pronounced change in crystal habit (i.e., re-crystallization) leading to preferred orientation of crystals in the X-ray beam, or an increase in the crystallinity of $\delta$-mannitol. The change to the habit of the crystals would manifest itself in a change to the intensity of certain reflections i.e. the hkl values $\left(\begin{array}{lll}0 & 2 & 0\end{array}\right)\left(\begin{array}{ll}7 \mathrm{~nm}^{-1}\end{array}\right)$ and $\left(\begin{array}{ll}0 & 1\end{array}\right.$ 1) $\left(14 \mathrm{~nm}^{-1}\right)$ for the $\delta$-form. The morphology of the $\delta$-form reported in ${ }^{20}$ indicated that the crystals were a lath (crystal dimensions: $0.42 \times 0.12 \times 0.01 \mathrm{~mm}$ ) which is also consistent with the calculation of the Bravais, Friedel, Donnay and Harker (BFDH) morphology model derived from the crystal structure. This crystallite shape is relatively flat with the $\left(\begin{array}{lll}0 & 2 & 0\end{array}\right)$ face being dominant. It should be noted, however, that 2-dimensional patterns demonstrate a minimal change in the texture of mannitol rings (Figure S8); this observation does not support the "change in the preferred orientation" hypothesis. An alternative explanation is a true increase in mannitol crystallinity; it is also consistent with one literature report where an amorphous mannitol was detected by Raman spectroscopy in frozen mannitol solutions even after annealing at $-10^{\circ} \mathrm{C}^{15}$. Therefore, these results indicate that amorphous-to-crystalline transformation (and an increase in mannitol crystallinity with the corresponding growth of crystalline XRD peaks) could take place during heating in 2 steps, with the second step taking place at $>-10^{\circ} \mathrm{C}$. Follow-up studies would be warranted to investigate 2-step crystallization of mannitol, as it would have both fundamental (in particular, considering a possibility of 2 amorphous phases of mannitol ${ }^{21}$ which could have different crystallization patterns) and practical consequences. From the industrial perspectives, it would mean that annealing after initial freezing step (as common in pharmaceutical manufacture) might not be sufficient to ensure completion of mannitol crystallization, and promoting mannitol crystallization during cooling (by utilizing lower cooling rate or step-wise cooling, as was also proposed earlier ${ }^{13}$ ) can be used instead. 

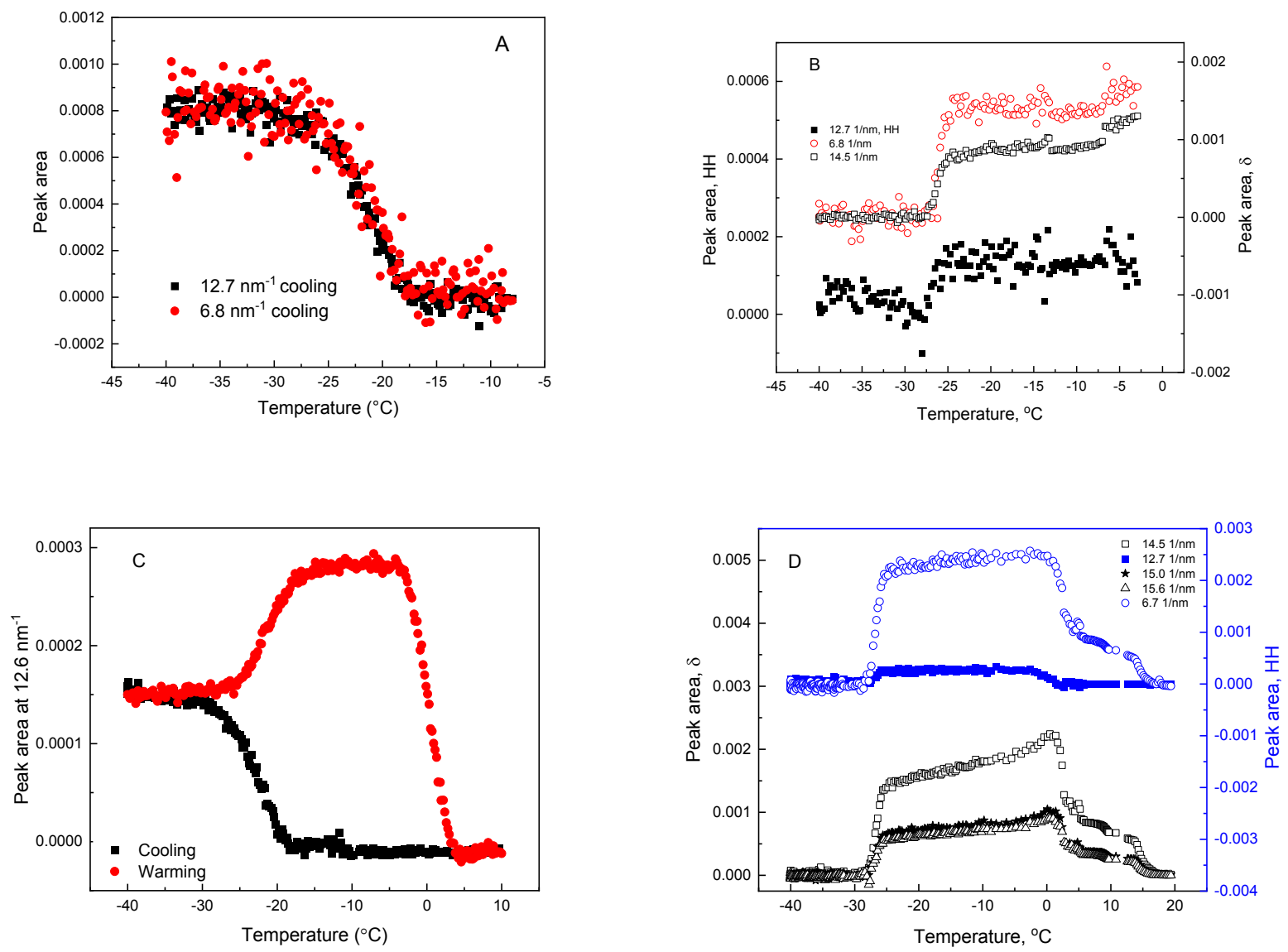

Figure 3. Change in the peak areas $\left(\mathrm{mm}^{-1} * \mathrm{~nm}^{-1}\right.$, i.e., $\left.10^{-6} \mathrm{~nm}^{-2}\right)$ of $X$-ray diffraction peaks of different forms of crystalline mannitol with temperature (A): the HH during cooling of 10\% mannitol solution at $0.5^{\circ} \mathrm{C} / \mathrm{min} .(B)$ : the $\delta$ (right axis) and $\mathrm{HH}$ (left axis) during heating of 10\% mannitol; cooling rate $5{ }^{\circ} \mathrm{C} / \mathrm{min}$; (C): the HH during cooling and heating of $5 \%$ mannitol, cooling rate $5^{\circ} \mathrm{C} / \mathrm{min}$; (D): the $\delta$ (left axis), $\mathrm{HH}$ (right axis) during heating of $20 \mathrm{wt} \%$ mannitol, cooling rate $5^{\circ} \mathrm{C} / \mathrm{min}$.

\section{Cooling rates}

Cooling rates are expected to have a major impact on crystallization behavior. For any particular system, if the cooling rate is lower than a critical cooling rate, crystallization would take place during cooling. Otherwise, crystallization during cooling is avoided, and the sample could crystallize during subsequent heating/annealing instead. ${ }^{1}$ For mannitol/water solutions, the literature data ${ }^{12,22}$ indicate that cooling rates of $20^{\circ} \mathrm{C} / \mathrm{min}$ would favor a retention of an amorphous structure of mannitol during freezing (Figure 4A); in these cases, crystallization takes 
place during subsequent warming. At cooling rates of 5 and $10^{\circ} \mathrm{C} / \mathrm{min}$, crystallization was observed in some studies while avoided in other cases. Furthermore, a partial crystallization of mannitol during cooling can take place in this intermediate range of the cooling rates, as reported in ${ }^{6,13}$, and also observed in this study ( $5 \%$ mannitol at $5{ }^{\circ} \mathrm{C} / \mathrm{min}$, Figure 1$)$. In this study, at a rate of $0.5^{\circ} \mathrm{C} / \mathrm{min}$, mannitol crystallized during cooling. This is consistent with the literature reports, where cooling at $1{ }^{\circ} \mathrm{C} / \mathrm{min}$ and below resulted in mannitol crystallization during cooling in the majority of cases. Figure 4A demonstrates that there are no obvious correlations between mannitol concentration and critical cooling rates. Note also that cooling rate is not the only factor which defines crystallization behavior; in particular, sample volume could have a significant impact. As an example, a lower critical cooling rate $\left(0.35 \pm 0.15^{\circ} \mathrm{C} / \mathrm{min}\right)$ was determined for $5 \%$ mannitol solution ${ }^{23}$; in that study, larger sample volumes (1 to $3 \mathrm{~mL}$ ) were used.

\section{Role of thermodynamics}

While the kinetics plays a major role in mannitol crystallization, thermodynamics aspects of phase relationships provide a critical baseline in any studies of crystallization behavior. In aqueous systems, condensed phase equilibria at sub-zero temperatures are commonly presented by temperature-composition (T-x) phase diagrams. A complete T-x phase diagram of mannitolwater system is not readily available from the literature, while there are reports on various elements of the phase diagram, as follows. Temperature dependence of solubility of mannitol was reported in several publications, ${ }^{24-28}$ although solid form of mannitol was not confirmed. Mannitol solubility line has also been presented in a partial phase diagram ${ }^{18}$, however, neither mannitol form nor the source of the solubility data were provided, and therefore these solubility data are not included in the current analysis. Eutectic temperature was reported to be $-2.24^{\circ} \mathrm{C}^{28}$ although in the study the mannitol form in the eutectic was not specified. An important insight on the low-temperature mannitol phases was reported by Mehta et al ${ }^{13}$ using $10 \mathrm{wt} \%$ mannitol solution. It was observed that annealing during cooling at $-10^{\circ} \mathrm{C}$ produced $\alpha$-mannitol, whereas annealing at $-20^{\circ} \mathrm{C}$ resulted in $\mathrm{HH}$. At the intermediate annealing temperature of $-15^{\circ} \mathrm{C}$, two experiments were conducted and produced different outputs; in one case, a mixture of $\beta$ mannitol and $\mathrm{HH}$ was observed whereas pure $\mathrm{HH}$ form formed in the second experiment. Based on these results, it was suggested that there is a transition temperature between a (non-specified) anhydrous mannitol form and $\mathrm{HH}$ at approx. $-15^{\circ} \mathrm{C}^{13}$. Theoretical support for the transition 
between hydrated and anhydrous phases was provided by Dierks \& Korter; the Gibbs free energy of mannitol HH was shown to exceed the free energy of the anhydrous forms, which are "hydrated" with the same number of water molecules above $253 \mathrm{~K}$, therefore indicating a phase transition of $\mathrm{HH}$ to an anhydrous mannitol $+1 / 2 \mathrm{H}_{2} \mathrm{O}$ around $253 \mathrm{~K}\left(-20^{\circ} \mathrm{C}\right){ }^{29}$ The phase diagram, which summarizes the literature data, is presented in Figure 4B, with two nonvariant points reflecting 3-phase equilibrium, eutectic $(\mathrm{Ih}+\beta$-mannitol + solution) and peritectic $(\beta$ mannitol $+\delta$-mannitol + solution). Eutectic $(7 \mathrm{wt} \%)$ and peritectic $(17 \mathrm{wt} \%)$ compositions have been estimated from the mannitol solubility curve at the eutectic temperature $\left(-2.2^{\circ} \mathrm{C}^{28}\right)$ and peritectic temperature (based on the finding of an enantiotropic $\beta-\delta$ relationship at approx. $25^{\circ} \mathrm{C} .{ }^{29}$

Additional input into relative thermodynamic stability around the eutectic temperature can be gained from data presented in Figures 3 and S6, which allow detection of an onset of reduction in crystallinity (melting/dissolution) of various mannitol polymorphs. The onsets for reduction in the crystallinity are detected at $-2.2 \pm 0.6^{\circ} \mathrm{C}, 0.6^{\circ} \mathrm{C}$, and $3.3^{\circ} \mathrm{C}$ for $\mathrm{HH}, \delta$, and $\beta$-forms, respectively. There are 2 possible reasons for the transitions detected at temperatures $>0^{\circ} \mathrm{C}$, either a temperature lag between the sample temperature and the Linkam stage temperature, or/and slow rate or dissolution of mannitol crystals. Therefore, the "onsets in crystallinity reduction" should not be interpreted as the true eutectic temperatures. Nevertheless, the rank order of the temperatures between different crystalline forms of mannitol is probably meaningful, suggesting that $\beta$-mannitol is the thermodynamically stable form in the eutectic with Ih, whereas the $\mathrm{HH}+\mathrm{Ih}+$ solution represents a metastable phase combination at the eutectic point. This conclusion agrees with the phase diagram (Figure 4B). 

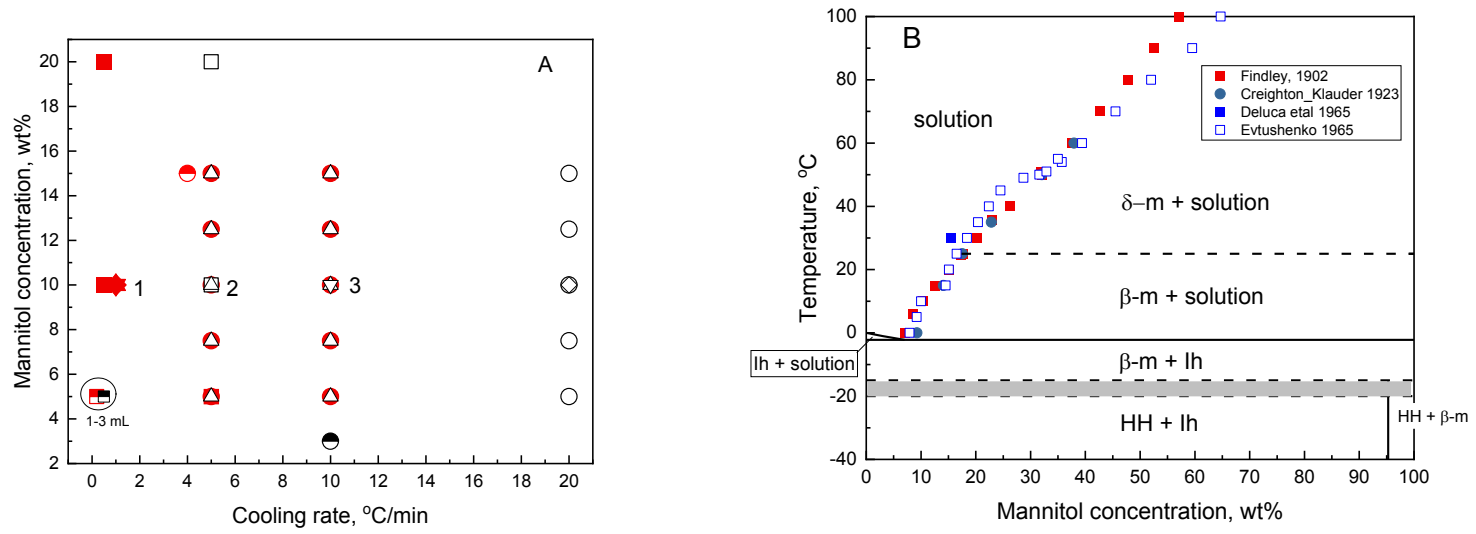

Figure 4. (A) Map of crystalline/amorphous mannitol formed during cooling at different rates and solution concentrations. Red filled and half-filled symbols: crystalline mannitol; black open and half-open symbols: amorphous mannitol. Sources for the filled symbols: squares: this study; circles: 22 (DSC data); up triangles: 22 (XRD data); down triangles: ${ }^{15}$; rhomb: ${ }^{12}$; half-filled squares: ${ }^{23}$; half-filled circle black: ${ }^{33}$; half-filled circle red: ${ }^{6}$. Multiple datasets correspond to points 1-3 as

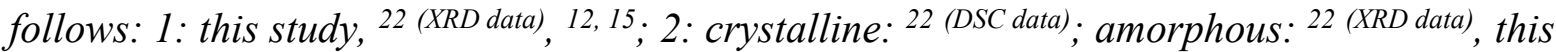

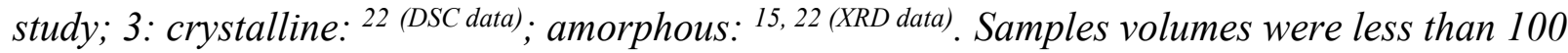
$\mu l$ in the majority of cases, with the exception of the points in circle. (B) Temperaturecomposition- phase diagram of water-mannitol system. Symbols: mannitol solubility. The horizontal dash lines represent phase relationships between different forms of mannitol as follows: HH/anhydrous mannitol $\left(-15^{\circ} \mathrm{C}^{13}\right.$, with the anhydrous mannitol phase assumed to be $\beta$ form based on $\left.{ }^{29}\right)$, $H H / \beta$-mannitol $\left(-20^{\circ} C^{29}\right)$, and $\beta$-mannitol $/ \alpha$-mannitol $\left(25^{\circ} C^{29}\right)$. The grey rectangle indicates uncertainty in the position of the border between $\mathrm{HH}+\mathrm{Ih}$ and $\beta$-mannitol + Ih fields. The dash lines indicate elements without experimental confirmation of the phase relationships. See text for other details on the construction of the phase diagram.

Experimental observations of mannitol crystallization, however, do not follow the equilibrium phase relationships as outlined in the phase diagram. Comparison of the experimentallyobserved sequence of the phase transitions during cooling with the sequence which would be expected under equilibrium conditions (i.e., based on the phase diagram) is provided in Table 1. The crystallization sequences appear to follow Ostwald's rule of stages, ${ }^{30}$ which states that solid first formed on crystallization of a solution or a melt would be the least stable polymorph. It 
should be stressed, however, that such behavior is not necessarily reproducible; it is well known that polymorph control is an extremely challenging topic, as perfectly summarized in ${ }^{31}$ : "we did the experiment last week and got this result, and now we cannot repeat it!" (see also ${ }^{32}$ ).

Table 1. Phase transition sequences during cooling of mannitol solutions.

\begin{tabular}{|l|l|l|}
\hline $\begin{array}{l}\text { Mannitol } \\
\text { concentration }\end{array}$ & From the phase diagram & Experimental* \\
\hline $5 \mathrm{wt} \%$ & Solution $\rightarrow \mathrm{Ih}+$ solution $\rightarrow \mathrm{Ih}+\beta \rightarrow \mathrm{Ih}+\mathrm{HH}$ & Solution $\rightarrow \mathrm{Ih}+$ solution $\rightarrow \mathrm{Ih}+\mathrm{HH}$ \\
\hline $10 \mathrm{wt} \%$ & Solution $\rightarrow \beta+$ solution $\rightarrow \mathrm{Ih}+\beta \rightarrow \mathrm{Ih}+\mathrm{HH}$ & Solution $\rightarrow \mathrm{Ih}+$ solution $\rightarrow \mathrm{Ih}+\mathrm{HH}$ \\
\hline $20 \mathrm{wt} \%$ & $\begin{array}{l}\text { Solution } \rightarrow \delta+\text { solution } \rightarrow \beta+\text { solution } \rightarrow \\
\mathrm{Ih}+\beta \rightarrow \mathrm{Ih}+\mathrm{HH}\end{array}$ & $\begin{array}{l}\text { Solution } \rightarrow \mathrm{Ih}+\text { solution } \rightarrow \beta+\mathrm{Ih} \rightarrow \\
\mathrm{Ih}+\beta+\mathrm{HH}\end{array}$ \\
\hline
\end{tabular}

* cooling rates $5^{\circ} \mathrm{C} / \mathrm{min}\left(5 \mathrm{wt} \%\right.$ mannitol) and $0.5^{\circ} \mathrm{C} / \mathrm{min}$ (10 and $\left.20 \mathrm{wt} \%\right)$

The phase diagram graphically illustrates the fact that a co-existence of three crystalline phases (two mannitol forms and ice) in a finite temperature range in a binary system is prohibited at the equilibrium by the phase rule. The simultaneous observation of two mannitol forms (both in this study and in multiple literature reports) therefore reflects a non-equilibrium nature of the system under conditions of the experiment. Nevertheless, metastable forms can be kinetically stable, in particular in mannitol case, ${ }^{14}$ as also observed in this study. Indeed, no transition from one form to another is observed during heating over the entire temperature range studied (Figures 3B, 3D), in which no increase in crystallinity for a particular form at the expense of a second form is detected. Note however, that a different observation was reported using Raman spectroscopy, ${ }^{33}$ with a transition from $\delta$ - to $\alpha$-form taking place during annealing of $3 \%$ mannitol solution at $30^{\circ} \mathrm{C}$. It is possible that the lower mannitol concentration / higher water content in the sample in that study could contribute to the kinetic instability of the $\delta$-form, via two physical mechanisms, that is, a larger ice/solution interface, and a higher local pressure during water-to-ice transformation.

To summarize, mannitol crystallization during freezing of aqueous solutions is strongly dependent on the cooling rate, Crystallization of mannitol can be initiated during cooling, if the cooling rate is lower than the critical cooling rate; otherwise, mannitol remains amorphous 
during freezing, and crystallizes during subsequent heating. Crystallization during cooling takes place at higher temperatures, above $-20^{\circ} \mathrm{C}$, whereas crystallization during heating commences above $-30^{\circ} \mathrm{C}$, coinciding a sharp decrease in the viscosity of the freeze-concentrated solution. This difference in the crystallization temperature can have a major practical consequence for manufacturing of pharmaceutical formulations containing mannitol. Thermodynamics relationships in the mannitol-water system are presented in the form of T-x phase diagram.

The unexpected finding of the study is the observation of the 2-step mannitol crystallization pattern, with the $2^{\text {nd }}$ step taking place close to the eutectic temperature. The $2^{\text {nd }}$ step could be either due to preferred orientation of crystallites via a change in the crystal habit, possibly as the result of Ostwald ripening, or a real increase in the fraction of crystalline phase. While the former appears to be more plausible mechanism, the diffraction data do not support it, and therefore increase in the crystallinity cannot be ruled out at this point. The $2^{\text {nd }}$ crystallization step would also be consistent with previous report of amorphous mannitol after annealing of the frozen solutions at $-10^{\circ} \mathrm{C},{ }^{15}$ and the suggestion that mannitol could form 2 amorphous phases. ${ }^{21}$ This possibility is intriguing and warrants follow-up investigations.

\section{ACKNOWLEDGEMENTS.}

We acknowledge the European Synchrotron Radiation Facility for provision of synchrotron radiation facilities. The study was supported by ESRF proposal LS-2652. IDHO funded by EPSRC (Grant ref: EP/N015401/1). We would like to thank the International Strategic Partnership between University of Strathclyde and Nanyang Technological University Singapore for funding LEC.

\section{ASSOCIATED CONTENT. Supporting Information.}

The Supporting Information is available free of charge on the ACS Publications website as follows:

Tabulated values of mannitol crystallization temperature ranges, onset of ice nucleation temperatures, position of peaks of different crystalline forms of mannitol; Description of thermal events during cooling/heating of mannitol/water mixtures; examples of DSC curves for mannitol/water mixtures; Solid-liquid state diagram of mannitol-water system and its 
description; Figures with examples of synchrotron X-ray diffraction patterns of various mannitol/water mixtures at different temperatures and cooling rates, and with overlays of selected experimental patterns with reference patterns for mannitol crystalline forms; Figure with peak areas of X-ray diffraction peaks of different forms of crystalline mannitol for 3 experimental conditions; examples of 2-dimensional WAXS patterns.

\section{EXPERIMENTAL METHODS.}

D-mannitol USP was obtained from Sigma-Aldrich (St. Louis, MO). Solutions were prepared using deionized water and aliquots were introduced in $1.0 \mathrm{~mm}$ quartz capillary tubes (WJM, Germany). WAXS experiments were performed on ID02 beamline at the European Synchrotron Radiation Facility (ESRF) in Grenoble, France ${ }^{17}$ at a radiation wavelength $\lambda$ of $0.995 \AA$. Twodimensional ced images were collected using a Rayonix LX-170HS (WAXS) camera at a sample to detector distance of $12.2 \mathrm{~cm}$. The exposure time was adjusted to use the dynamic of the detector $(<0.1 \mathrm{~s})$. Standard detector corrections were applied to the two-dimensional images before azimuthal integration in order to obtain the corresponding 1-dimensional (1D) X-ray diffraction curves. The q-scale was calibrated using secondary standard. The samples were filled into $1 \mathrm{~mm}$ quartz capillaries and loaded onto a Linkam temperature stage THMS600/TMS94 operated at cooling rates of 0.5 and $5^{\circ} \mathrm{C} / \mathrm{min}$ between $20^{\circ} \mathrm{C}$ and $-40^{\circ} \mathrm{C}$, and a heating rate of $1^{\circ} \mathrm{C} / \mathrm{min}$. The WAXS patterns were recorded every $2 \mathrm{~s}$ for $5 \%$ mannitol; $20 \mathrm{~s}$ for $10 \%$ mannitol at $0.5^{\circ} \mathrm{C} / \mathrm{min}$ and $10-15 \mathrm{~s}$ for $10 \%$ mannitol at $5^{\circ} \mathrm{C} / \mathrm{min} ; 5 \mathrm{~s}$ for $20 \%$ mannitol at $5^{\circ} \mathrm{C} / \mathrm{min}$ and 20 s for $20 \%$ mannitol at $0.5^{\circ} \mathrm{C} / \mathrm{min}$. Mannitol reference patterns were taken from single crystal determinations of the various solid forms curated in the Cambridge Structural Database, ${ }^{20,} 34-38$ and Ih pattern $(223 \mathrm{~K})$ was calculated from data reported in ${ }^{39}$. Identification of crystalline forms of mannitol was performed by overlaying experimental patterns with reference patterns; two patterns were also analyzed using Rietveld method and one pattern with Pawley fit (Figure S3). Mannitol crystallinity was estimated by integrating selected peaks in the WAXS patterns using batch peak analysis function in Origin 2018 software.

\section{References.}


(1) Shalaev, E.; Franks, F. Solid-Liquid State Diagrams in Pharmaceutical Lyophilisation: Crystallisation of Solutes, in: Progress in Amorphous Food and Pharmaceutical Systems, H Levine (Ed.), The Royal Society of Chemistry, 2002, pp. 200-215.

(2) Tsironi, I.; Schlesinger, D.; Spah, A.; Eriksson, L.; Segadc, M.; Perakis, F. Brine rejection and hydrate formation upon freezing of $\mathrm{NaCl}$ aqueous solutions. Phys. Chem. Chem. Phys. 2020, 22, 7625-7632.

(3) Jochem, M.; Körber, Ch. Extended phase diagrams for the ternary solutions $\mathrm{H}_{2} \mathrm{O}-\mathrm{NaCl}-$ glycerol and $\mathrm{H}_{2} \mathrm{O}-\mathrm{NaCl}$-hydroxyethylstarch (HES) determined by DSC. Cryobiology 1987, 24, 513-536.

(4) Murray, B. J.; Bertram, A. K. Inhibition of solute crystallisation in aqueous $\mathrm{H}^{+}-\mathrm{NH}_{4}{ }^{+}-\mathrm{SO}_{4}{ }^{2-}$ $\mathrm{H}_{2} \mathrm{O}$ droplets. Phys. Chem. Chem. Phys. 2008, 10, 3287-3301.

(5) Williams, N. A.; Lee, Y.; Polli, G. P.; Jennings, T. A. The Effects of Cooling Rate on Solid Phase Transitions and Associated Vial Breakage Occurring in Frozen Mannitol Solutions. J. Parenter. Sci. Technol. 1986, 40, 135-141.

(6) Jiang, G.; Akers, M.; Jain M.; Guo, J.; Distler, A.; Swift, R.; Wadhwa, M.-V. S.; Jameel, F.; Patro, S.; Freund, E. Mechanistic Studies of Glass Vial Breakage for Frozen Formulations. I. Vial Breakage Caused by Crystallizable Excipient Mannitol. PDA J. Pharm. Sci. Technol. 2007, 61, 441-451.

(7) Izutsu, K.; Yoshioka, S.; Terao, T. Decreased Protein-Stabilizing Effects of Cryoprotectants due to Crystallization. Pharm. Res. 1993, 10, 1232-1237.

(8) Yu, L.; Milton, N.; Groleau, E. G.; Mishra, D. S.; Vansickle, R. E. Existence of a Mannitol Hydrate during Freeze-Drying and Practical Implications. J. Pharm. Sci. 1999, 88, 196-198.

(9) Nunes, C.; Suryanarayanan, R.; Botez, C. E.; Stephens, P. W. Characterization and Crystal Structure of D-Mannitol Hemihydrate, J. Pharm. Sci. 2004, 93, 2800-2809.

(10) Kim, A. I.; Akers, M. J.; Nail, S. L. The Physical State of Mannitol after Freeze-Drying: Effects of Mannitol Concentration, Freezing Rate, and a Noncrystallizing Cosolute, $J$. Pharm. Sci. 1998, 87, 931-935.

(11) Telang, C.; Yu, L.; Suryanarayanan, R. Effective Inhibition of Mannitol Crystallization in Frozen Solutions by Sodium Chloride. Pharm. Res. 2003, 20, 660-667.

(12) Cavatur, R. K.; Suryanarayanan, R. Characterization of Phase Transitions During FreezeDrying by In Situ X-ray Powder Diffractometry. Pharm. Dev. Techn. 1998, 3, 579-586. 
(13) Mehta, M.; Bhardwaj, S. P.; Suryanarayanan, R. Controlling the Physical Form of Mannitol in Freeze-Dried Systems. Eur. J. Pharm. Biopharm. 2013, 85, 207-213.

(14) Burger, A.; Henck, J.; Hetz, S.; Rollinger, J. M.; Weissnicht, A. A.; Stöttner, H. Energy/Temperature Diagram and Compression Behavior of the Polymorphs of D-mannitol. J. Pharm. Sci. 2000, 89, 457-468.

(15) Kauppinen, A.; Toiviainen, M.; Aaltonen, J.; Korhonen, O.; Jarvinen, K.; Juuti, M.; Pellinen, R.; Ketolainen, J. Microscale Freeze-Drying with Raman Spectroscopy as a Tool for Process Development. Anal. Chem. 2013, 85, 2109-2116.

(16) Kett, V. L.; Fitzpatrick, S.; Cooper, B.; Craig, D. Q. M. An Investigation into the Subambient Behavior of Aqueous Mannitol Solutions Using Differential Scanning Calorimetry, Cold Stage Microscopy, and X-Ray Diffractometry. J. Pharm. Sci. 92, 2003, 1919-1929.

(17) Narayanan, T.; Sztucki, M.; Van Vaerenbergh, P.; Leonardon, J.; Gorini, J.; Claustre, L.; Sever, F.; Morse, J.; Boesecke, P. A. Multipurpose Instrument for Time-Resolved UltraSmall-Angle and Coherent X-Ray Scattering. J. Appl. Cryst. 2018, 51, 1511-1524.

(18) Gatlin, L.; Deluca, P. P. A Study of the Phase Transitions in Frozen Antibiotic Solutions by Differential Scanning Calorimetry. PDA J. Pharm. Sci. Tech. 1980, 34, 398-408.

(19) Her, L.-M.; Nail, S.L. Measurement of Glass Transition Temperatures of FreezeConcentrated Solute by Differential Scanning Calorimetry. Pharm. Res. 1994, 11, 54-59.

(20) Fronczek, F.R.; Kamel, H.N.; Slattery, M. Three Polymorphs ( $\alpha, \beta$, and $\delta$ ) of D-Mannitol at 100 K. Acta Crystallogr., Sect. C: Cryst. Struct. Commun. 2003, 59, o567-o570 (CSD code DMANTL08).

(21) Zhu, M.; Wang, J.-Q.; Perepezko, J. H.; Yu, L. Possible Existence of two Amorphous Phases of D-Mannitol Related by a First-Order Transition. J. Chem. Phys. 2015, 142, 244504/1-244504/7.

(22) Cavatur, R. K.; Vemuri, N. M.; Pyne, A.; Chrzan, Z.; Toledo-Velasquez, D.; Suryanarayanan, R. Crystallization Behavior of Mannitol in Frozen Aqueous Solutions. Pharm. Res. 2002, 19, 894-900.

(23) Wang, Q.; Shalaev, E. Process Analytical Technology in Freeze-Drying: Detection of the Secondary Solute + Water Crystallization with Heat Flux Sensors. AAPS PharmSciTech, 2017, doi: 10.1208/s12249-017-0910-2. 
(24) Evtushenko, V. A.; Pankratova, O. I. Solubility of mannitol. II. Solubility of mannitol in water. Zhurnal Prikladnoi Khimii (Sankt-Peterburg, Russian Federation), 1965, 38, 454456.

(25) Findlay, A. The Solubility of Mannitol, Picric Acid, and Anthracene. J. Chem. Soc., Trans. 1902, $81,1217-1221$.

(26) Creighton, H. J. M.; Klauder Jr., D. S. Solubility of Mannite in Mixtures of Ethyl Alcohol and Water. J. Franklin Inst. 1923, 195, 687-691.

(27) Braham, J. M. Some Physical Properties of Mannite and its Aqueous Solutions. J. Am. Chem. Soc. 1919, 41, 11, 1707-1718.

(28) Deluca, P.; Lachman, L. Lyophilization of Pharmaceuticals. I. Effect of Certain PhysicalChemical Properties. J. Pharm. Sci. 1965, 54, 617-24.

(29) Dierks, T. M.; Korter, T. M. Origins of the Relative Stabilities of Anhydrous and Hydrated D-Mannitol Crystals. J. Phys. Chem. A, 2016, 120, 6629-6636.

(30) Cardew, P. T.; Davey, R. J. The Ostwald Ratio, Kinetic Phase Diagrams, and Polymorph Maps. Cryst. Growth \& Design, 2019, 19, 5798-5810.

(31) Dunitz, J. D., Bernstein, J. Disappearing Polymorphs. Acc. Chem. Res. 1995, 28, 193—200.

(32) Bucar, D.-K.; Lancaster, R. W.; Bernstein, J. Disappearing Polymorphs Revisited. Angew. Chem. Int. Ed. 2015, 54, 6972-6993.

(33) Beattie, J. R.; Barrett, L. J.; Malone, J. F.; McGarvey, J. J.; Nieuwenhuyzen, M.; Kett, V. L. Investigation into the Subambient Behavior of Aqueous Mannitol Solutions using Temperature-Controlled Raman Microscopy. Eur. J. Pharm. Biopharm. 2007, 67, 569-578.

(34) Kim, H. S.; Jeffrey, G.A.; Rosenstein, R. D. The crystal structure of the K form of dmannitol. Acta Crystallogr., Sect. B: Struct. Crystallogr. Cryst. Chem. 1968, 24, 1449-1455 (CSD code DMANTL01).

(35) Kaminsky, W.; Glazer, A. M. Crystal Optics of D-Mannitol, C6H14O6: Crystal Growth, Structure, Basic Physical Properties, Birefringence, Optical Activity, Faraday Effect, Electro-Optic Effects and Model Calculations. Zeitschrift fuer Kristallographie, 1997, 212, 283-296 (CSD code DMANTL07).

(36) CSD code DMANTL10: as DMANTL08 (delta-mannitol). 
(37) Nunes, C.; Suryanarayanan, R.; Botez, C. E.; Stephens, P. W. Characterization and Crystal Structure of D-Mannitol Hemihydrate. J. Pharm. Sci. 2004, 93, 2800-2809 (Hemihydrate, CSD code MAFSUI).

(38) Groom, C. R.; Bruno, I. J.; Lightfoot, M. P.; Ward, S. C. The Cambridge Structural Database. Acta Cryst. 2016, B72, 171-179.

(39) Peterson, S. W.; Levy, H. A. A Single-Crystal Neutron Diffraction Study of Heavy Ice. Acta Cryst. 1957, 10, 70-76. 